Pacific Journal of Mathematics

INTI IN A CLASS OF SET 


\section{FIXED POINTS IN A CLASS OF SETS}

D. R. SMART

\section{Theorem. A set of the form $X=A \cup \bigcup_{i \in J} B_{i}$ has the fixed point property if}

(i) $A$ is a closed simplex and each $B_{i}$ is a closed simplex;

(ii) $A \cap B_{i}$ is a single point $p_{i}$ for each $i$;

(iii) any arc in $X$ joining a point in some $B_{i}$ to a point in $X-B_{i}$ must pass through $p_{i}$.

( $J$ can be any index set. The topology on $X$ can be given by any metric satisfying (i) and (iii).)

The statement that $X$ has the fixed point property means that each continuous mapping of $X$ into $X$ has a fixed point. The theorem applies to many sets which are not locally connected so that even Lefschetz's fixed point theorem is inapplicable. Instead of assuming that the subsets $A$ and $B_{i}$ are simplices we could merely assume that each of these subsets is locally arcwise connected and has the fixed point property. The result should still be true if each point $p_{i}$ is replaced by a simplex $P_{i}$ but this generalization would require altogether different methods.

Proof of the theorem. Let $T$ be a continuous mapping of $X$ into $X$. We distinguish three cases.

Case 1. Suppose $T p_{i} \in B_{i}-\left\{p_{i}\right\}$ for some $i$. Then we will show that $T$ has a fixed point in $B_{i}$.

Define

$$
\begin{aligned}
& S: B_{i} \rightarrow B_{i} \text { by } \\
& S x=T x \text { if } T x \in B_{i} \\
& S x=p_{i} \text { if } T x \notin B_{i} .
\end{aligned}
$$

Then $S$ is continuous by Lemma 2 below.

Since $B_{i}$ has the fixed point property, $S x=x$ for some $x$ in $B_{i}$. Now $x \neq p_{i}$ (for $x=p_{i}$ would give $S p_{i}=p_{i}$, impossible since $\left.S p_{i}=T p_{i} \in B_{i}-\left\{p_{i}\right\}\right)$. Thus $S x \neq p_{i}$ so that $T x=S x=x$.

Case 2. Suppose $T p_{i}=p_{i}$ for some $i$. Then $p_{i}$ is a fixed point.

Case 3. Suppose $T p_{i} \in X-B_{i}$ for all $i$. Then we will show that $T$ has a fixed point in $A$. Define $R: A \rightarrow A$ by

$$
R x=T x \text { if } T x \in A .
$$




$$
R x=p_{i} \text { if } T x \in B_{i} .
$$

Then $R$ is continuous by Lemma 2 . Since $A$ has the fixed point property, $R$ has a fixed point in $A$. The fixed point $\xi$ cannot be a point $p_{i}$ since $R x=p_{i}$ only if $T x \in B_{i}$; and $T p_{i} \notin B_{i}$. Since the fixed point is not $p_{i}, T \xi \notin B_{i}$. Thus $T \xi \in A$ so that $T \xi=R \xi=\xi$.

Thus in each case $\mathrm{T}$ has a fixed point, which proves the theorem. The above proof depends on two lemmas.

LEMMA 1. If $z(t)$ is a continuous function on $[0,1]$ to a metric space and either

(i) $w(t)$ is a constant, or

(ii) $w(t) \equiv z(t)$ except on a non-overlapping sequence of intervals $\left[t_{2 n-1}, t_{2 n}\right](n \geqq 1)$ such that

$$
\begin{aligned}
& t_{1}=0 \text { and } w(t) \equiv z\left(t_{2}\right) \text { on }\left[t_{1}, t_{2}\right] \\
& t_{4}=1 \text { and } w(t) \equiv z\left(t_{3}\right) \text { on }\left[t_{3}, t_{4}\right]
\end{aligned}
$$

and for $n>2, z\left(t_{2 n-1}\right)=z\left(t_{2 n}\right)$ and $w(t) \equiv z\left(t_{2 n}\right)$ on $\left[t_{2 n-1}, t_{2 n}\right]$. Then $w(t)$ is continuous on $[0,1]$.

Proof. Obvious. (One proof is : if $z_{n}$ is the function obtained from $z$ by changing its value to that of $w$ on the first $n$ intervals, then $z_{n}$ is continuous. Also $z_{n} \rightarrow w$ uniformly on $[0,1]$ since the length of $\left[t_{2 n-1}, t_{2 n}\right]$ must tend to 0 .

Lemma 2. Let $Y$ be a closed simplex contained in a metric space $X$. Suppose that $X-Y$ is the union of disjoint sets $Z_{i}$, that $Z_{i} \cap Y$ is a one-point set $\left\{q_{i}\right\}$, and that any path from a point in a $Z_{i}$ to $a$ point in $X-Z_{i}$ must pass through $q_{i}$. Let $U$ be continuous on $Y$ $X$. Define $T$ by

$$
\begin{aligned}
& T y=U y \text { if } U y \in Y \\
& T y=q_{i} \text { if } U y \in Z_{i} .
\end{aligned}
$$

Then $T$ is continuous.

Proof. If $y_{n} \rightarrow y$ in $Y$ we must show that $T y_{n} \rightarrow T y$. Consider a path $g(t)$ in $Y(0 \leqq t \leqq 1)$ such that $g(0)=y$ and $g(1 / n)=y_{n}$. Writing $U g(t)=z(t)$ and $T g(t)=w(t)$ the conditions of Lemma 1 are satisfied. For if $w(t)$ differs from $z(t)$ the possibilities are: $z(t)$ could be in some $Z_{i}$ for all $t$, in which case $w(t)$ is a constant; otherwise, there is an initial interval $\left[0, t_{2}\right]$ where $z(t)$ is in some $Z_{i}$, and/or some intermediate intervals $\left[t_{2 n-1}, t_{2 n}\right]$ where $z(t)$ is in some $Z_{i(n)}$ and/or a final interval $\left[t_{3}, 1\right]$ where $z(t)$ is in some $Z_{j}$. By Lemma $1, w(t)$ is continuous. Thus $T g(1 / n) \rightarrow T g(0)$ as required. 
The theorem can be used to establish some pathological examples. (It seems that all of these are already known.)

I. There exists a noncompact set having the fixed point property. Take

$$
\begin{aligned}
& A=\{(x, y): 0 \leqq x \leqq 1, y=0\} \\
& B_{n}=\left\{(x, y): x=\frac{1}{n}, 0 \leqq y \leqq 1\right\} .
\end{aligned}
$$

(In this case $\bar{X}$ also has the fixed point property.)

II. There exists an unbounded set having the fixed point property. Take $A$ as above.

$$
B_{n}=\left\{(x, y): x=\frac{1}{n}, 0 \leqq y \leqq n\right\} .
$$

III. There exists a set with the fixed point property whose closure lacks this property. Take $X$ as in II.

IV. There exists a precompact set with the fixed point property, whose closure lacks this property.

Take

$$
\begin{aligned}
& A=\left\{e^{i \theta}: \frac{\pi}{2} \leqq \theta \leqq 2 \pi\right\} \\
& B_{n}=\left\{\left(1+\frac{\theta}{n}\right) e^{i \theta}: 0 \leqq \theta \leqq \frac{\pi}{2}\right\} .
\end{aligned}
$$

Several sets which have some interest in other contexts have the fixed point property in consequence of our theorem :-

V. The set

$$
A \cup \bigcup_{n=1}^{\infty} B_{n} \cup \bigcup_{n=1}^{\infty} C_{n}
$$

where $A$ is the unit interval, $B_{n}$ is a unit line segment sloping up from $(0,0)$ with slope $1 / n$, and $C_{n}$ is a unit line segment sloping up to $(0,1)$ with slope $1 / n$. (This is a non contractible set.)

Received August 10, 1966.

University of CaPe TOWN, Rondebosch 



\section{PACIFIC JOURNAL OF MATHEMATICS}

\section{EDITORS}

\section{H. ROYDEN}

Stanford University

Stanford, California

J. P. JANS

University of Washington

Seattle, Washington 98105

\section{J. DUGUNDJI}

Department of Mathematics

Rice University

Houston, Texas 77001

RICHARD ARENS

University of California

Los Angeles, California 90024

ASSOCIATE EDITORS

E. F. BECKENBACH

B. H. NeumanN

F. WoLF

K. YosidA

\section{SUPPORTING INSTITUTIONS}

\author{
UNIVERSITY OF BRITISH COLUMBIA \\ CALIFORNIA INSTITUTE OF TECHNOLOGY \\ UNIVERSITY OF CALIFORNIA \\ MONTANA STATE UNIVERSITY \\ UNIVERSITY OF NEVADA \\ NEW MEXICO STATE UNIVERSITY \\ OREGON STATE UNIVERSITY \\ UNIVERSITY OF OREGON \\ OSAKA UNIVERSITY \\ UNIVERSITY OF SOUTHERN CALIFORNIA
}

\author{
STANFORD UNIVERSITY \\ UNIVERSITY OF TOKYO \\ UNIVERSITY OF UTAH \\ WASHINGTON STATE UNIVERSITY \\ UNIVERSITY OF WASHINGTON \\ AMERICAN MATHEMATICAL SOCIETY \\ CHEVRON RESEARCH CORPORATION \\ TRW SYSTEMS \\ NAVAL ORDNANCE TEST STATION
}




\section{Pacific Journal of Mathematics}

\section{Vol. 23, No. 1 \\ March, 1967}

M. J. C. Baker, A spherical Helly-type theorem ................... 1

Robert Morgan Brooks, On locally m-convex*-algebras.............. 5

Lindsay Nathan Childs and Frank Rimi DeMeyer, On automorphisms of separable algebras ...................................

Charles L. Fefferman, A Radon-Nikodym theorem for finitely additive set

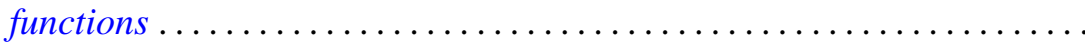

Magnus Giertz, On generalized elements with respect to linear

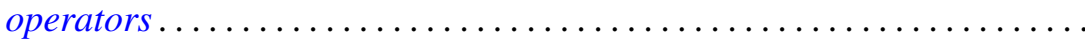

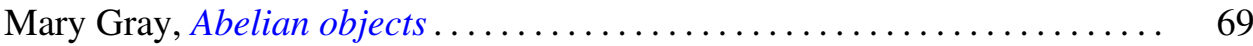

Mary Gray, Radical subcategories.............................. 79

John A. Hildebrant, On uniquely divisible semigroups on the two-cell . . . . . 91

Barry E. Johnson, AW*-algebras are $\mathrm{QW}^{*}$-algebras ............... 97

Carl W. Kohls, Decomposition spectra of rings of continuous functions . . . . 101

Calvin T. Long, Addition theorems for sets of integers .............. 107

Ralph David McWilliams, On $w^{*}$-sequential convergence and quasi-reflexivity ................................... 113

Alfred Richard Mitchell and Roger W. Mitchell, Disjoint basic

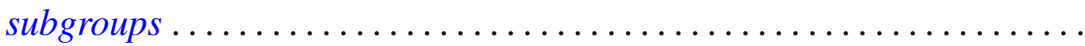

John Emanuel de Pillis, Linear transformations which preserve hermitian and positive semidefinite operators .

Qazi Ibadur Rahman and Q. G. Mohammad, Remarks on Schwarz's lemma

Neal Jules Rothman, An $L^{1}$ algebra for certain locally compact topological semigroups ...

F. Dennis Sentilles, Kernel representations of operators and their adjoints ...

D. R. Smart, Fixed points in a class of sets

K. Srinivasacharyulu, Topology of some Kähler manifolds

Francis C.Y. Tang, On uniqueness of generalized direct decompositions .

171 Albert Chapman Vosburg, On the relationship between Hausdorff dimension and metric dimension . 